UCRL-JC-122508

PREPRINT

CONF- $960264--2$

\title{
Electrical Resistance Tomography for Imaging the Spatial Distribution of Moisture in Pavement Sections
}

M. Buettner

A. Ramirez

RECEIVED

W. Daily

FER $\cap$ b $19 y b^{\circ}$

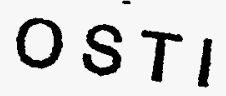

This paper was prepared for submittal to the

Structural Materials Technology an NDT Conference

San Diego, CA

February 20-23, 1996

November 8, 1995

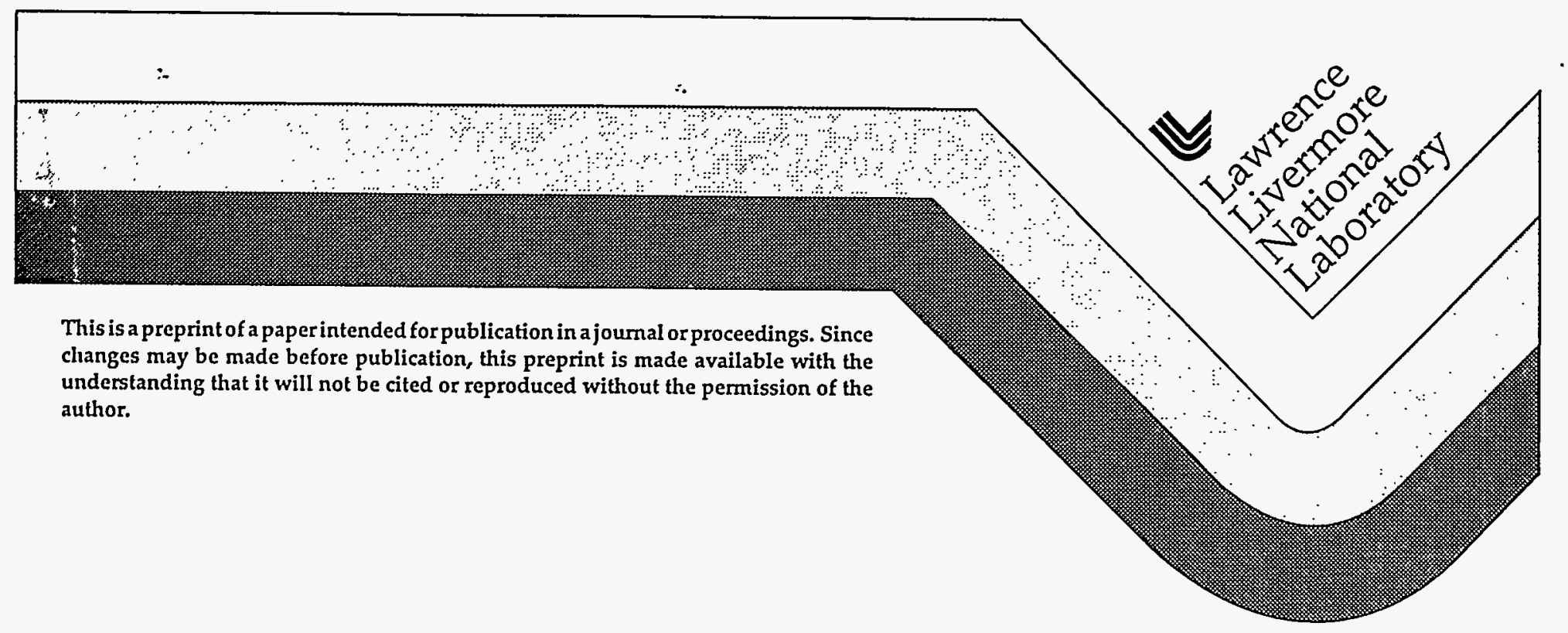




\section{DISCLAIMER}

This document was prepared as an account of work sponsored by an agency of the United States Government. Neither the United States Govermment nor the University of California nor any of their employees, makes any warranty, express or implied, or assumes any legal liability or responsibility for the accuracy, completeness, or usefulness of any information, apparatus, product, or process disclosed, or represents that its use would not infringe privately owned rights. Reference herein to any specific commercial product, process, or service by trade name, trademark, manufacturer, or otherwise, does not necessarily constitute or imply its endorsement, recommendation, or favoring by the United States Government or the University of Califomia. The views and opinions of authors expressed herein do not necessarily state or reflect those of the United States Government or the University of California, and shall not be used for advertising or product endorsement purposes. 
Electrical Resistance Tomography for Imaging the Spatial Distribution of Moisture in Pavement Sections

Michael Buettner

Abe Ramirez

William Daily 


\begin{abstract}
Electrical Resistance Tomography (ERT) was used to image spatial moisture distribution and movement in pavement sections during an infiltration test. ERT is a technique for determining the electrical resistivity distribution within a volume from measurement of injected currents and the resulting electrical potential distribution on the surface. The transfer resistance (ratio of potential to injected current) data are inverted using an algorithm based on a finite element forward solution which is iteratively adjusted in. a least squares sense until the measured and calculated transfer resistances agree to within some predetermined value.

Four arrays of ERT electrodes were installed in vertical drill holes $1.22 \mathrm{~m}(4 \mathrm{ft})$ placed at the corners of a square $61 \mathrm{~cm}(2 \mathrm{ft})$ on a side into a pavement section which is used for a truck scale ramp on U.S. Highway 99 just north of Sacramento, CA. Water was introduced slowly into the pavement through a shallow hole in the center of this pattern and ERT data were collected in various planes as the water infiltrated into the pavement and subgrade materials over a period of several hours.

The ERT data were inverted, and the resulting images show 1) the basic structure of the pavement section and 2) the movement of water through the.image planes as a function of time during infiltration. An interesting result is that the water does not appear to drain from the section toward the shoulder as had been expected based on the design.
\end{abstract}

\title{
CONCEPT OF ERT
}

ERT is a method for determining the electrical resistivity distribution in a volume based on discrete measurements of current and voltage on the boundary. Resistivity data can be taken in a variety of configurations, including borehole-to-borehole, borehole-to-surface, or pure surface. Detailed technical concepts and theory used for ERT can be found elsewhere (Daily and Owen, 1991; Daily et al., 1992).

In order to obtain an image of a body from surface measurements, a number of electrodes are placed on the surface of the body and in electrical contact with it. A pair of adjacent electrodes are driven by a known current, and the resulting voltage difference is measured between other pairs of electrodes. Then, the known current is applied to another

Michael Buettner, Lawrence Livermore National Laboratory, 7000 East Avenue, Livermore, CA 94550

Abe Ramirez, 7000 East Avenue, Livermore, CA 94550

William Daily, 7000 East Avenue, Livermore, CA 94550 
pair of electrodes and the voltage is again measured between other pairs. This procedure is repeated until current has been applied to all pairs of electrodes. The ratio of a voltage at one pair of terminals to the current causing it is a transfer resistance. For $n$ electrodes there are $n(n-3) / 2$ independent transfer resistances.

The next step is to calculate the distribution of resistivity in the volume given the measured transfer resistances and to construct an image. However, the calculation for the distribution of resistivity is highly nonlinear because the currents flow along the paths of least resistance and are dependent on the resistivity distribution. Finite element algorithms and least square methods are used to invert the transfer resistances.

Image construction can be on the same finite element mesh used to calculate the measurements or on a different array. An absolute image shows a resistivity structure whereas a comparison image shows changes in resistivity. Comparison images can be used to study dynamic processes in structures, such as imbibition, by comparing data taken at different times. This paper presents both absolute images and comparison images.

A more detailed description of the theory can be found in a companion paper entitled "Electrical Resistance Tomography for Imaging Concrete Structures" (Buettner, Ramirez, and Daily) from this cunference.

\section{INFILTRATION EXPERIMENT}

A set of ERT electrodes was installed in September, 1992 on the truck scale pull-off ramp just north of Riego Road on Highway 99 near the Sacramento, CA Metro Airport. The pavement structural section has open graded asphalt concrete $(\mathrm{OGAC}, 1.8 \mathrm{~cm})$, dense graded AC (DGAC, $19.8 \mathrm{~cm}$ ), asphalt treated permeable base (ATPB, $7.6 \mathrm{~cm}$ ), aggregate base (AB, $13.7 \mathrm{~cm}$ ) and lime treated subgrade (LTS, $30.5 \mathrm{~cm}$ ) over native soil as illustrated in Figure 1 .

Figure 2 shows a plan view of four, $10.2 \mathrm{~cm}$ diameter boreholes where electrode arrays were inserted. Four image planes were defined by four linear arrays of electrodes placed into holes at corners of a $61 \mathrm{~cm}$ square. The electrode arrays extended to $122 \mathrm{~cm}$ below the pavement surface. There were 12 electrodes in each hole and 5 surface electrodes on each edge of the square. Surface electrodes were placed into $1.3 \mathrm{~cm}$ diameter holes drilled into the bottom of sawcuts on the pavement surface. These holes extended about $5.1 \mathrm{~cm}$ into the DGAC layer. The sawcut was approximately $5.1 \mathrm{~cm}$ wide and $5.1 \mathrm{~cm}$ deep.

Electrodes in boreholes and at the surface were spaced at every $10.2 \mathrm{~cm}$. One $10.2 \mathrm{~cm}$ diameter hole was drilled at the center of the square (see Figure 2) down to the bottom of ATPB layer for a water infiltration experiment. The water infiltration experiment was planned to better understand water flow (vertical and horizontal direction) in this drained pavement section.

Two kinds of backfill material were tried in this experiment: cement mortar and excavated pavement materials. Cement mortar with 1 to 3 ratio (by weight) was used with a water-cement ratio of 0.5. Boreholes No. 1 and 2 (see Figure 2) were backfilled with the excavated native soil, LTS and AB materials which were removed from the holes during drilling. The space of ATPB, DGAC and OGAC was filled with cold AC patching material. Boreholes No. 3 and 4 were filled with cement mortar up to the top of the aggregate base and cold AC patching material filled the remaining space to the surface. A steel rod was used to compact the backfill materials to eliminate air pockets around the electrodes and to make good contact between the backfill materials and electrodes. A commercial concrete patching and cold AC patching materials were used to fill the sawcut trench. . Before introducing water into the center hole, ERT data were collected for baseline images. Baseline images of the 1-2, 2-3 and 3-4 planes are shown in Figure 3 and the images are matched along their common edges. The images clearly show the resistivity structure with high resistivity in upper layers and low resistivity in the LTS and native soil. Also, the OGAC layer and the interface between OGAC and DGAC show low resistivity in all three planes. This effect is 

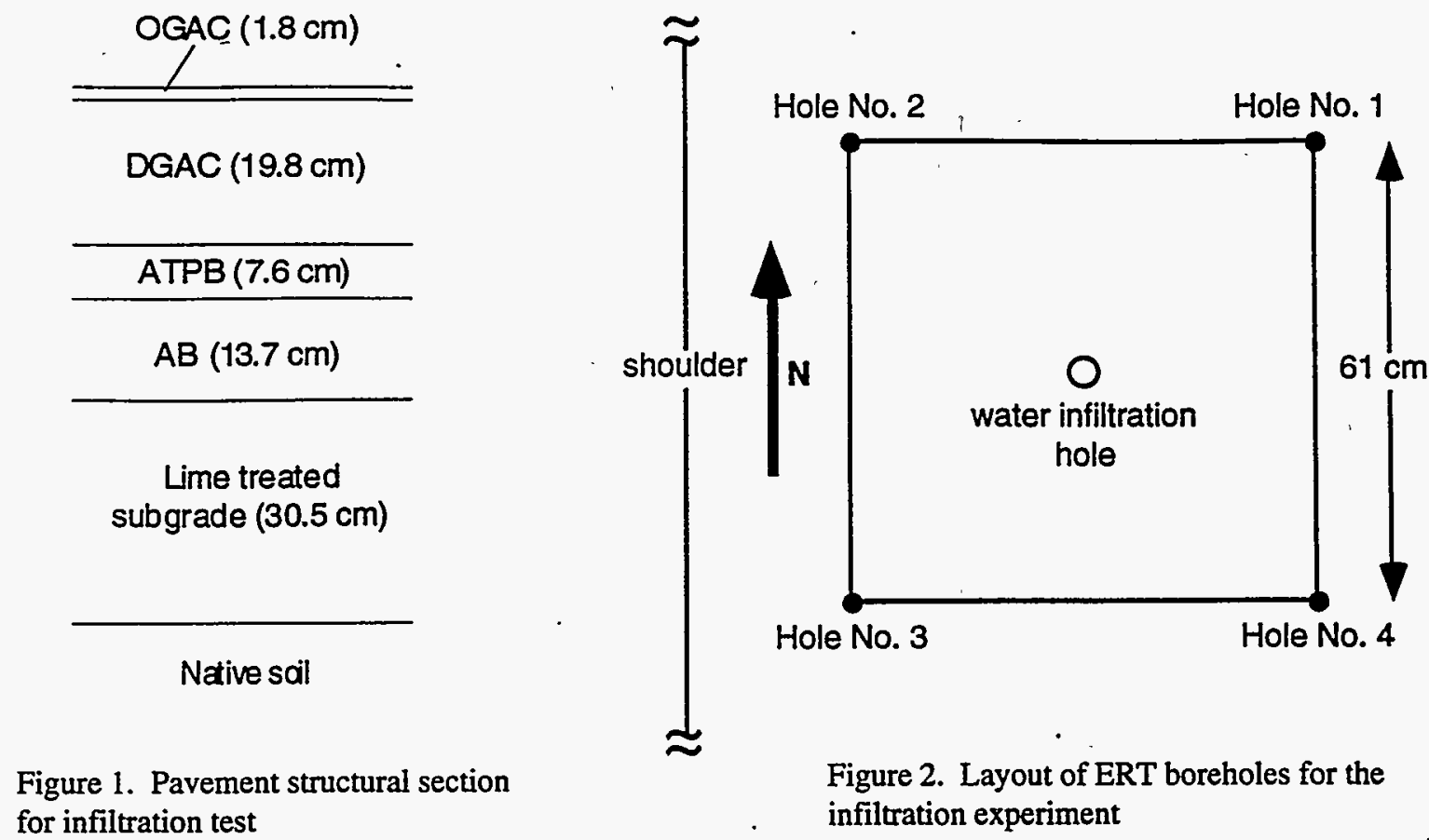

for infiltration test

Figure 2. Layout of ERT boreholes for the infiltration experiment

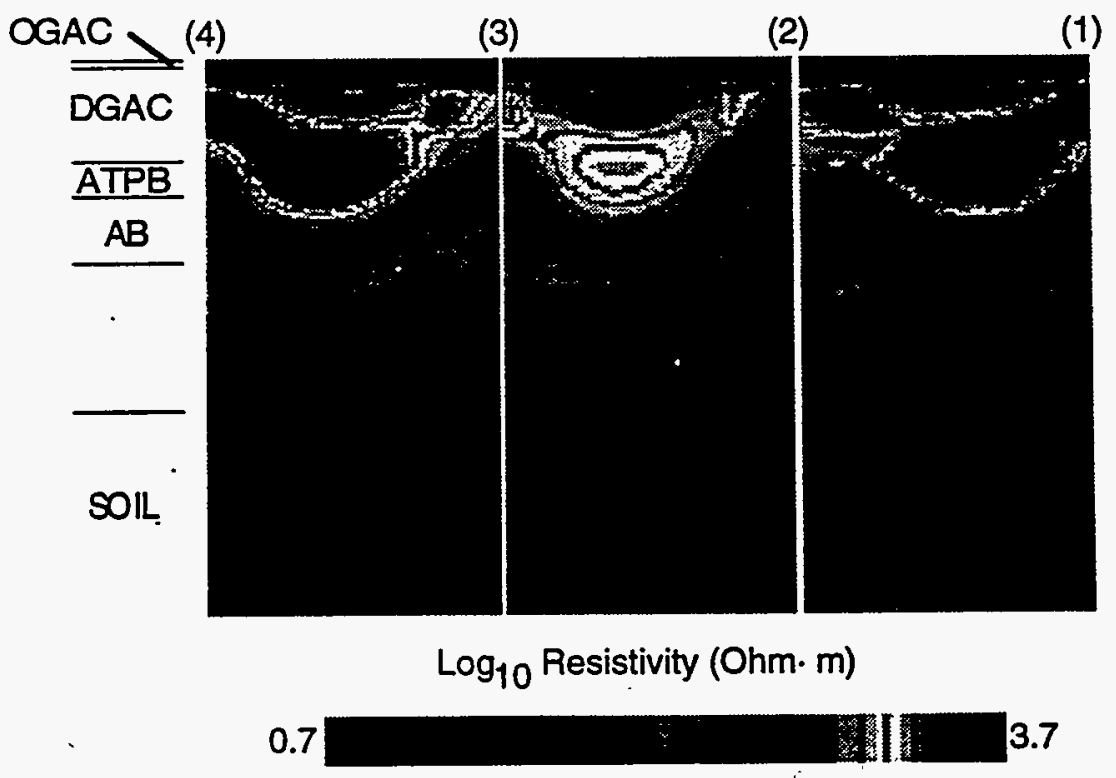

Figure 3. Baseline ERT images before water infiltration 
probably not real and is thought to be caused by the low-resistivity AC patching material used to backfill the surface sawcuts.

The infiltration experiment was conducted on' April 20,1993. During a 6:5 hour time period, approximately 5.5 gallons of water was introduced uniformly and slowly into the pavement through the center hole. Data were collected at several times during the infiltration period. The change in resistivity associated with moisture movement was imaged as a function of time. Four complete data sets were collected at $0914,1017,1231$ and 1443 hours for the $2-3$ plane because the researchers expected most of the water to drain through this plane. One data set was collected for the $3-4$ plane at 1336 and one for the $1-2$ plane at 1125 . Because each data set required about one hour to collect, the images

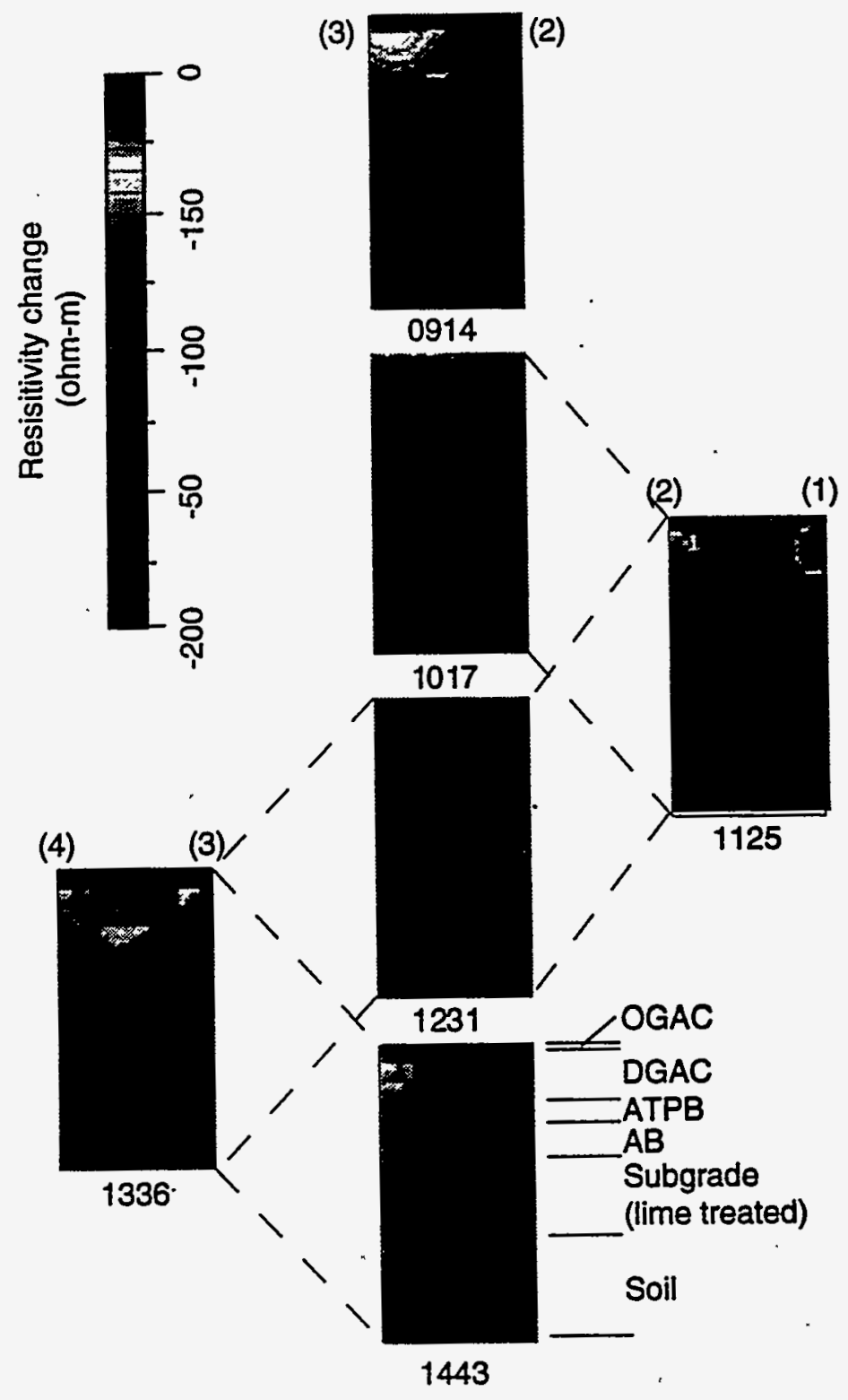

Figure 4. Comparison images during water infiltration 
represent a time average. Figure 4 shows a sequence of comparison images which show differences from the baseline conditions. That is, if there were no changes in resistivity because of water infiltration, the images would be a uniform single color. Progressive decreases in resistivity (i.e., increase in moisture) appear as progressively lighter as shown on the grayscale.

\section{DISCUSSION AND CONCLUSIONS}

The sequence of images for the 2 - 3 plane shows that at 0914 there is a decrease in resistivity (interpreted as water flow) in the pavement structural section around the No. 3 borehole. At 1017 this feature has disappeared but there is perhaps some ponding of water across the section and in the LTS. By 1231 this ponding disappeared and there is more moisture movement around the borehole No. 3. Finally at 1443 there appears to be more moisture movement around the borehole No. 3 much like at 0914 . The sequence of four ERT images does not show what could be termed a steady state flow phenomenon which is expected during slow, constant infiltration.

The single image in the $3-4$ plane at 1336 shows moisture movement through the pavement structural section. The image of this plane matches well along its borehole No. 3 edge with the $2-3$ plane image at 1443 . The other single image of the $1-2$ plane at 1125 shows moisture movement, though not as pronounced as the one for $3-4$ plane at 1336 . The images in Figure 9 do not appear to show that infiltrated water drained preferentially to the shoulder through the $2-3$ plane.

There are several factors which complicate the interpretation of the images from Fig. 4. Among them are 1) possible leaks or water movement between layers via boreholes, 2) the image reconstructions assume 2-dimensional water flow when the flow is really 3-dimensional, and 3) the data acquisition time is probably too long (about 1 hour) compared to the time scale of changes in the flow pattern in the pavement structure. Because of 3) each image must be thought of as a time-average of the processes involved.

In spite of the difficulties, is appears that ERT can be used to delineate moisture movement in pavement structures. Future work should seek to ameliorate the above problems by 1) improving ERT electrode placement in boreholes, 2) inverting the data with a true 3-dimensional approach, and 3) by speeding up the data acquisition process.

\section{APPLICATIONS}

ERT imaging has potential applications relating to structures, soils, pavements, and environmental remediation and monitoring. ERT should be applicable for detecting cracking in structures through the changes in resistivity that occur when water infiltrates cracks. In addition, ERT should be capable of detecting rebar location and possibly the state of corrosion. Applications of ERT for soils include monitoring slope stability and the stability of footings. In pavements, ERT has already been used to monitor moisture content and movement (see companion paper). Finally, ERT has been used to detect and monitor leaks from storage tanks, for monitoring thermal processes during environmental remediation, and for detecting and monitoring contaminants in soil and groundwater.

\section{ACKNOWLEDGMENT}

John Carbino provided technical support for this project. This work was performed under the auspices of the U.S. Department of Energy by Lawrence Livermore National Laboratory under contract no. W-7405-Eng-48. 


\section{REFERENCES}

Daily, W. D., and E. Owen. 1991. "Cross-borehole Resistivity Tomography," GEOPHYSICS, 56(8): 12281235.

Daily, W. D., A. Ramirez, D. LaBrecque and J. Nitao. 1992. "Electrical Resistivity Tomography of Vadose Water Movement," Water Resources Research, 28(5):1429-1442. 




$$
1
$$

